\title{
Travel in Pregnancy: The Impact of Zika
}

\author{
Erin E. Curcio, Jonathan D. Baum, Debra Gussman, Mark Martens \\ Department of Obstetrics \& Gynecology, Jersey Shore University Medical Center, Neptune, NJ, USA \\ Email: Erin.Curcio@hackensackmeridian.org
}

How to cite this paper: Curcio, E.E., Baum, J.D., Gussman, D. and Martens, M. (2017) Travel in Pregnancy: The Impact of Zika. Open Journal of Obstetrics and Gynecology, 7, 1064-1071.

https://doi.org/10.4236/ojog.2017.710107

Received: July 18, 2017

Accepted: October 13, 2017

Published: October 16, 2017

Copyright (c) 2017 by authors and Scientific Research Publishing Inc. This work is licensed under the Creative Commons Attribution International License (CC BY 4.0).

http://creativecommons.org/licenses/by/4.0/

\begin{abstract}
OBJECTIVE: The purpose of our study was to examine current travel patterns and behaviors of pregnant women. METHODS: We developed a questionnaire adapted from a publication by Kingman and Economides to examine the travel behavior of women during pregnancy in a suburban community. RESULTS: A convenience sample of 102 patients completed the travel questionnaire. Forty-six (45.1\%) traveled during the current pregnancy. Thirty-one (30.4\%) traveled more than once. A total of 257 trips were taken by the participants: $113(43.9 \%)$ trips were taken in the first trimester, $87(33.8 \%)$ in the second and $59(22.9 \%)$ in the third trimester. Trip length ranged from 2-90 days with a mean of 11 days. Reasons for travel included: 193 (75.1\%) for leisure, 37 (14.4\%) work related, 10 (3.9\%) trips for emergencies, and $3(0.4 \%)$ trips for relocation. Eighteen women (17.6\%) traveled internationally. One (1.0\%) woman was hospitalized while traveling. Manner of travel was as follows: car 167 (65.0\%), plane 67 (26.1\%), train $13(5.1) \%$, bus $10(3.9 \%)$ and none by boat. Nineteen (41.3\%) women sought travel advice. Thirteen $(68.4 \%)$ asked for advice from a doctor, 2 (10.5\%) from a nurse, 2 (10.5\%) from family and/or friends, 1 (5.3\%) from the Internet and 1 (5.3\%) from a travel book. Seventeen (37\%), traveled without suitable insurance. DISCUSSION: Travel rates during pregnancy have remained surprisingly stable over the past 60 years. Almost $50 \%$ of our cohort traveled during pregnancy, and the majority did not seek advice prior to travel. In light of new infectious disease threats, obstetric practice and advice needs reassessment. The majority of travel during pregnancy remains optional. Improved patient education and consultations prior to travel could decrease health risks.
\end{abstract}

\section{Keywords}

Travel, Pregnancy, Zika

\section{Introduction}

The modern obstetric patient is mobile. Within hours, a pregnant woman and 
her fetus can be transported almost anywhere in the world. While travel in pregnancy is generally considered safe, not all destinations are. The recent Ebola and Zika viral outbreaks serve as a stark reminder. While Ebola was largely limited to Africa, Zika's spread to the United States and effect on the fetus sparked an entirely new chapter in travel medicine. The current epidemic of the Zika virus was first reported in Brazil in April 2015 and by early 2016 the World Health Organization (WHO) declared the outbreak a Public Health Emergency of International Concern [1]. The Centers for Disease Control and Prevention (CDC) recommended that all pregnant women consider postponing travel to 76 countries where viral transmission is ongoing [2]. Several popular vacation destinations were included in the list of areas to avoid, and almost overnight, routine travel became something to fear for pregnant women and their partners as sexual transmission has now been documented as well [3] [4].

Women were suddenly asking their prenatal care providers about travel during pregnancy. While information regarding travel and pregnancy is easily found on the Internet, the scientific evidence is limited with few peer-reviewed publications available. The purpose of our study was to examine current travel patterns and behaviors of pregnant women and compare this with prior studies.

\section{Methods}

A literature search utilizing the search terms "travel and pregnancy" and a PubMed search for "travel patterns in pregnancy" were performed. Given the heterogeneity of the available studies we defined travel as an overnight stay away from home that took the patient away from her obstetric provider. Pregnant women receiving prenatal care at our center were invited to participate at their convenience. After 36 weeks of gestation, participating subjects responded to a questionnaire about their travel experience during the current pregnancy. The questionnaire was adapted from a publication by Kingman and Economides and used with the authors' permission [5]. Demographic information was obtained. Questions were asked about trimester of travel, route of travel, duration of stay, purpose of travel, destination (international or domestic) and any medical or obstetrical complications experienced during travel.

Descriptive statistics were used to compare the cohorts. Frequency and percentage were used to summarize the discrete variables. Chi-square test was used to compare the proportions between groups. A p-value of or less than 0.05 was used to indicate statistical significance. An online application was used for data analysis [6].

Given the new public health concerns facing pregnant women and those planning pregnancy we chose to examine the travel behavior of women during pregnancy in our suburban New Jersey population and compare this behavior with prior studies. This study was approved by the Meridian Health Institutional Review Board (IRB). 


\section{Results}

A review of the literature identified less than 50 peer reviewed articles about travel and pregnancy and most of these studies focused on air travel and/or thromboembolism, and one compared self-reported travel distance to GPS data [7].

Beach (1947) examined the subject of travel in pregnancy to determine the dangers [8]. Travel was defined as a trip of greater than 100 miles. He studied 681 women at the Chicago Lying-In Hospital over a period of 2.5 months after their deliveries. He reported that 309 of 681 (45.4\%) patients had traveled. He wrote, "The greatest part of the traveling was done by automobile and train, very little by bus." Three patients went on boat trips. Less than $1 \%$ of travel was by plane.

Guilbeau et al. (1953) wrote, "Most obstetricians have little occasion to observe the effects of travel on their patients, since the general population as a whole is more or less static, and parents are usually settled permanently by the time a pregnancy is considered" [9]. They identified 1917 women who traveled a minimum of 300 miles during pregnancy between 1951-1953 and received care at two Air Force Hospitals in Alabama and Mississippi. Of this cohort, 1526 (79.6\%) traveled by automobile, $244(12.8 \%)$ by train, and $147(7.7 \%)$ by airplane.

Freeman et al. (2004) asked the question "Does air travel affect pregnancy outcome?" [10]. They studied 222 women over a 6 month period in the District of Columbia. One hundred eighteen (53.2\%) flew at least once during pregnancy. No adverse outcomes were noted in pregnancies reaching 20 weeks gestation.

Chibber (2006) conducted a retrospective analysis of air travel in 992 of Saudi Arabian women and reported that 546 (55.0\%) traveled by plane at least once during pregnancy [11]. Their data suggested a three week shorter gestation in those women who traveled via airplane.

In our current survey, 102 pregnant women agreed to participate. Their mean and median age was 28 with a range of $17-44$ years. Parity ranged from 0 to 8 with a median of 1 (Table 1 ). Forty-six (45.1\%) women reported traveling during the current pregnancy. Thirty-one (30.4\%) traveled more than once. A total of 257 trips were taken by the participants: 113 (43.9\%) trips were taken in the first trimester, $87(33.8 \%)$ in the second and $59(22.9 \%)$ in the third trimester (Table 2). Mean trip length ranged from 2 - 90 days with a mean of 11 days. Reasons for travel were as follows: 193 (75.1\%) for vacation and visiting family, $37(14.4 \%)$ trips related to work, 10 (3.9\%) trips were for emergencies, and 3 (0.4\%) trips involved relocation. Eighteen women (17.6\%) traveled outside the United States. One (1.0\%) woman was hospitalized for preterm labor (and discharged undelivered) while traveling. Manner of travel was as follows: car 167 (65.0\%), plane 67 (26.1\%), train $13(5.1 \%)$, bus 10 (3.9\%) and none by boat. Nineteen $(41.3 \%)$ women sought travel advice. Of those, thirteen (68.4\%) asked for advice from a doctor, 2 (10.5\%) from a nurse, 2 (10.5\%) from family and/or friends, 1 (5.3\%) from the Internet and 1 (5.3\%) from a travel book. A disturbing number of women, 17 (37\%), traveled without suitable insurance. A comparison of travel by cohort is seen in Table 3 . 
Table 1. Patient demographics.

\begin{tabular}{ccc}
\hline & Mean & Range \\
\hline Age (Years) & 28.2 & $17-44$ \\
Gravidity & 3.2 & $1-12$ \\
Parity & 1.8 & $0-8$ \\
Commute (miles) & 17.9 & $0-100$ \\
Commute (minutes) & 41.9 & $0-300$ \\
Length of travel (days) & 9.6 & $2-90$ \\
\hline
\end{tabular}

Table 2. Travel by trimester.

\begin{tabular}{ccc}
\hline & $\begin{array}{c}\text { Patients who Travelled } \\
(\mathrm{n}=102)\end{array}$ & $\begin{array}{c}\text { Trips taken } \\
(\mathrm{n}=257)\end{array}$ \\
\hline 1st Trimester & $34.3 \%$ & $43.9 \%(113)$ \\
2nd Trimester & $30.0 \%$ & $33.8 \%(87)$ \\
3rd Trimester & $21.0 \%$ & $22.9 \%(59)$ \\
\hline
\end{tabular}

Table 3. Comparison of cohorts.

\begin{tabular}{ccccc}
\hline Author & Year & Travel During Pregnancy & Percent & $p$-value \\
\hline Beach & 1947 & $309 / 681$ & $45.4 \%$ & 0.96 \\
Freeman & 2004 & $118 / 222$ & $53.2 \%$ & 0.18 \\
Chibber & 2006 & $546 / 992$ & $55.0 \%$ & 0.06 \\
Curcio et al. & 2016 & $46 / 102$ & $45.1 \%$ & - \\
\hline
\end{tabular}

\section{Discussion}

Travel information for women during pregnancy and their healthcare providers is readily available from American College of Obstetricians [12] [13] [14], the CDC [15] and Gynecologists, the Center for Disease Control and the Royal College of Obstetricians and Gynaecologists [16]. There are recommendations regarding immunizations for women who travel during pregnancy [17] [18] [19]. There are articles looking at the risks to pregnant women by travel type such as thromboembolic disease [20] and radiation exposure while flying [21] [22]. Certain travel behaviors such as wilderness travel [23], scuba diving [24], and the impact of altitude [25] have been examined. Specific pregnancy conditions such as placental abruption [26] [27], preterm delivery [28], and labor far from home [29] have also been studied. Recommendations exist regarding air [30] and sea travel [31].

Despite the extensive literature on the effects of travel on pregnancy, there has been little study of the frequency and extent of travel in women during pregnancy. The recent Ebola and Zika viral outbreaks have complicated the issue of travel for everyone. The obstetric provider must be able to answer travel questions which have become an important part of prenatal care in response to the 
spread of Zika virus across the hemisphere. Thus, our goal was to study the travel patterns and behavior of women during pregnancy and compare these to prior studies with the hope of improving obstetric advice and counselling prior to travel.

Travel in pregnancy appears to have remained surprisingly stable over the past 60 years. About half of pregnant women travel and most travels are uncomplicated. However, travel to certain geographies may increase the risk of infectious disease, especially during pregnancy. We have seen an increase in risk from serious endemic outbreaks across the globe including Ebola virus, Zika virus, Severe Acute Respiratory Syndrome (SARS), Middle East Respiratory Syndrome Coronavirus (MERS-CoV), Dengue virus, Chikungunya virus, Asian influenza virus and a multitude of other viral, bacterial, and parasitic protozoal pathogens.

Couples planning a pregnancy will need to be counselled on both the risks of travel and any potential threat or hazard that waits at their destination. A complete medical history must now include travel history for the patient and partner and perhaps other family members as well.

The high prevalence of travel in our study $(45.1 \%)$ is consistent with the findings of Beach, Freeman et al., and Chibber et al. (Table 3). Comparison of these studies suggests that the rate of travel during pregnancy has remained stable since the 1940s. In our cohort, the majority of travel during pregnancy was for leisure. This is consistent with the general pattern of American travel overall [32]. Travel occurred in all trimesters. As expected, travel during the third trimester was less prevalent and of shorter duration. Many women made multiple trips during pregnancy and most traveled via automobile and airplane. Complications were rare.

The most concerning finding in the current study was that almost $60 \%$ of women traveling during pregnancy did not seek advice prior to travel, although, almost $80 \%$ of those who did receive advice, did so from their obstetric provider or nurse, which is encouraging. The majority of travel during pregnancy remains optional, involving family visits or vacation, for which a pre-trip consultation could significantly impact the health risks to the mother and baby.

We recommend:

1) Patients be asked early in prenatal care about any travel plans during pregnancy.

2) Discuss safe travel practices as part of routine prenatal education.

3) Medical records should be readily available to all patients (as illness while traveling is not predictable).

4) Healthcare providers be familiar with CDC travel warnings so they can advise women who plan to travel and provide up to date information and links to appropriate websites.

5) Patients notify their obstetric providers if they become ill during travel.

6) Patients notify their obstetric provider of an upcoming office visit due to illness. Offices need to be prepared for these illness visits in order to provide for a safe office environment for all patients. Use of designated waiting rooms and 
examination rooms may help limit the exposure and spread of communicable disease in the office setting.

7) Providing information and links to websites to patients planning long distance travel in which prolonged periods of immobilization are anticipated.

In summary, travel during pregnancy has been common for decades however, only recently have new infectious threats triggered a reassessment of obstetric practice and advice. The changing global environment now mandates that we look at the evolving infectious and non-infectious risks of travel. In the near future, the safety of autonomous vehicles, underwater and space travel will need to be examined thoroughly as the modern cohort of women continues to travel during pregnancy and ventures further and further away from home and their obstetric providers.

\section{References}

[1] World Health Organization (2016) WHO Director-General Summarizes the Outcome of the Emergency Committee Regarding Clusters of Microcephaly and Guillain-Barré Syndrome. World Health Organization.

http://www.who.int/mediacentre/news/statements/2016/emergency-committee-zika -microcephaly/en/

[2] CDC (2016) Travelers' Health. CDC Issues Interim Travel Guidance Related to Zika Virus for 14 Countries and Territories in Central and South America and the Caribbean. US Department of Health and Human Services, CDC, Atlanta, GA. http://wwwnc.cdc.gov/travel/notices.

[3] D’Ortenzio, E., Matheron, S., Lamballerie, X.D., et al. (2016) Evidence of Sexual Transmission of Zika Virus. New England Journal of Medicine, 374, 2195-2198. https://doi.org/10.1056/NEJMc1604449

[4] Mansuy, J.M., Dutertre, M., Mengelle, C., et al. (2016) Zika Virus: High Infectious Viral Load in Semen, a New Sexually Transmitted Pathogen? The Lancet Infectious Diseases, 16, 405. https://doi.org/10.1016/S1473-3099(16)00138-9

[5] Kingman, C.E. and Economides, D.L. (2003) Travel in Pregnancy: Pregnant Women's Experiences and Knowledge of Health Issues. Journal of Travel Medicine, 10, 330-333. https://doi.org/10.2310/7060.2003.9353

[6] Social Science Statistics Easy Chi-Square Calculator. http://www.socscistatistics.com/tests/chisquare/Default.aspx

[7] Wu, J., Jiang, C., Jaimes, G., et al. (2013) Travel Patterns during Pregnancy: Comparison between Global Positioning System (GPS) Tracking and Questionnaire Data. Environmental Health.

[8] Beach Jr., W.B. (1947) Travel in Pregnancy. American Journal of Obstetrics and Gynecology, 54, 1054-1057. https://doi.org/10.1016/S0002-9378(16)39722-8

[9] Guilbeau, J.A. and Turner, J.L. (1953) The Effect of Travel upon the Interruption of Pregnancy: An Analysis of 1,917 Cases with Minimum Journeys of 300 Miles. American Journal of Obstetrics and Gynecology, 66, 1224-1230. https://doi.org/10.1016/0002-9378(53)90160-4

[10] Freeman, M., Ghidini, A., Spong, C.Y., et al. (2004) Does Air Travel Affect Pregnancy Outcome? Archives of Gynecology and Obstetrics, 269, 274-277. https://doi.org/10.1007/s00404-003-0579-5

[11] Chibber, R., Al-Sibai, M.H. and Qahtani, N. (2006) Adverse Outcome of Pregnancy 
Following Air Travel: A Myth or a Concern? Australian and New Zealand Journal of Obstetrics and Gynaecology, 46, 24-28. https://doi.org/10.1111/j.1479-828X.2006.00508.x

[12] American College of Obstetricians and Gynecologists (2009) Air Travel during Pregnancy. ACOG Committee Opinion No. 443. Obstetrics \& Gynecology, 114, 954-955. https://doi.org/10.1097/AOG.0b013e3181bd1325

[13] American College of Obstetricians and Gynecologists (2016) Car Safety for Pregnant Women, Babies, and Children. ACOG FAQ018.

http://www.acog.org/Patients/FAQs/Car-Safety-for-Pregnant-Women-Babies-andChildren

[14] American College of Obstetricians and Gynecologists (2016) Travel during Pregnancy. ACOG FAQ055.

http://www.acog.org/Patients/FAQs/Travel-During-Pregnancy

[15] Centers for Disease Control and Prevention (2013) Pregnant Travelers. https://wwwnc.cdc.gov/travel/page/pregnant-travelers

[16] Hezelgrave, N.L., Whitty, C.J.M., Shennan, A.H. and Chappell, L.C. (2011) Advising on Travel during Pregnancy. BMJ, 342, d2506-d2506.

[17] Morof, D. and Carroll, D. (2015) Advising Travelers with Specific Needs. Centers for Disease Control and Prevention.

https://wwwnc.cdc.gov/travel/yellowbook/2016/advising-travelers-with-specific-nee ds/pregnant-travelers

[18] Caroll, I.D. and Williams, D.C. (2008) Pre-Travel Vaccination and Medical Prophylaxis in the Pregnant Traveler. Travel Medicine and Infectious Disease, 6, 259-275.

[19] D'Acremont, V., Tremblay, S. and Genton, B. (2008) Impact of Vaccines Given during Pregnancy on the Offspring of Women Consulting a Travel Clinic: A Longitudinal Study. Journal of Travel Medicine, 15, 77-81. https://doi.org/10.1111/j.1708-8305.2007.00175.x

[20] Cannegieter, S.C. and Rosendaal, F.R. (2013) Pregnancy and Travel-Related Thromboembolism. Thrombosis Research, 131, S55-S58.

[21] Friedberg, W., Copeland, K., et al. (2000) Radiation Exposure during Air Travel: Guidance Provided by the Federal Aviation Administration for Air Carrier Crews. Health Physics, 79, 591-595. https://doi.org/10.1097/00004032-200011000-00018

[22] Barish, R.J. (2004) Radiation Risk from Airline Travel. Journal American College of Radiology, 1, 784-785.

[23] Carroll, I.D. and Van Gompel, A. (2005) The Pregnant Wilderness Traveler. Travel Medicine and Infectious Disease, 3, 225-238.

[24] St Leger Dowse, M., Gunby, A., Moncad, R., Fife, C. and Bryson, P. (2006) Scuba Diving and Pregnancy: Can We Determine Safe Limits? Journal of Obstetrics and Gynaecology, 26, 509-513. https://doi.org/10.1080/01443610600797368

[25] Jean, D. and Moore, L.G. (2012) Travel to High Altitude during Pregnancy: Frequently Asked Questions and Recommendations for Clinicians. High Altitude Medicine \& Biology, 13, 73-81. https://doi.org/10.1089/ham.2012.1021

[26] Matzkel, A. and Lurie, S. (1991) Placental Abruption Associated with Air Travel. A Case Report and an Overview on Safety of Air Travel in Pregnant Women. Journal of Perinatal Medicine, 19, 317-320.

[27] Fletcher, H.M., Wharfe, G.H. and Mitchell, S.Y. (2003) Placental Separation from a Seat Belt Injury Due to Severe Turbulence during Aeroplane Travel. Journal of $O b$ stetrics and Gynaecology, 23, 73-74. https://doi.org/10.1080/0144361021000055576 
[28] Easa, D., Pelke, S., et al. (1984) Unexpected Preterm Delivery in Tourists: Implications for Long-Distance Travel during Pregnancy. Journal of the California Perinatal Association, 14, 264-267.

[29] Tennyson, M. (2000) Labor at 20,000 Feet. American Journal of Nursing, 100, 49-52. https://doi.org/10.1097/00000446-200009000-00038

[30] Magann, E.F. and Chauhan, S.P. (2010) Air Travel and Pregnancy Outcomes: A Review of Pregnancy Regulations and Outcomes for Passengers, Flight Attendants, and Aviators. Obstetrical \& Gynecological Survey, 65, 396-402. https://doi.org/10.1097/OGX.0b013e3181e572ae

[31] Dahl, E. (2007) Pregnancy at Sea-24th Week of Gestation Is the Limit. International Maritime Health, 58, 195-198.

[32] U.S. Travel Association (2015) U.S. Travel Answer Sheet. https://www.ustravel.org/answersheet 